\title{
The Effect of Post Type, Category and Posting Day on User Interaction Level on Facebook
}

\author{
Irena Pletikosa Cvijikj, Erica Dubach Spiegler, Florian Michahelles \\ Information Management \\ ETH Zurich \\ Zurich, Switzerland \\ \{ipletikosa, edubach, fmichahelles\}@ethz.ch
}

\begin{abstract}
Social networks are becoming an additional marketing channel that could be integrated with the traditional ones as a part of the marketing mix. However, traditional advertising techniques are not applicable for the social media platforms, resulting in companies experimenting with many different approaches, thus shaping a successful social media strategies based on their own experiences. To gain a more general understanding, our study analyses the effects of moderator post characteristics, such as post type, category and posting day, on the user interaction in terms of number of comments and likes, as well as interaction duration. We present the results obtained from 14 Facebook brand pages. Our results show that there is a significant effect of the post type and category on number of likes and comments as well as on interaction duration. Based on these results, we could show clear evidence of moderator posts increasing fan activity. We discuss the implications of our findings for social media marketing.
\end{abstract}

\section{Keywords-social media marketing; social networks; Facebook}

\section{INTRODUCTION}

Marketing has recently undergone significant changes in the way information is delivered to the customers [1]. Social networks as a part of Web 2.0 technology provide the technological platform for individuals to connect, produce and share content online. As such, they offer the potential for (1) advertising - by facilitating viral marketing, (2) product development - by involving consumers in the design process and (3) market intelligence - by observing and analyzing the user generated data [2].

Social media marketing is the intentional influencing of consumer-to-consumer communications through professional marketing techniques. The advantage of social media as an additional marketing channel is that it can be used to communicate globally and to enrich communication toward consumers at the personal level [1]. Companies, across all industries, are starting to understand the possibilities of social media marketing. Many brand pages have already been created in social network sites like Facebook. However, how these pages are being used, what their potentials are and how consumers interact remains largely unknown [2].

The goal of our paper is to evaluate the effect of the three main characteristics of moderator posts on the user interaction level on a sponsored Facebook brand page: (1) post type, (2) post category and (3) weekday of the posting. We focus on the moderator posts since they represent the "company's voice" and are clearly distinguished from posts shared by page fans through the name of the "poster" which corresponds to the page/company name. We measure the user interaction level through (1) the number of comments on individual post, (2) number of likes and (3) interaction duration. The questions we try to answer are:

- RQ1: Do different types of moderator posts cause different levels of user interaction?

- RQ2: Do different categories of moderator posts cause different levels of user interaction?

- RQ3: Do different posting weekdays cause different levels of user interaction?

In our previous work we have investigated the effect of the moderator posts on a single brand page [14]. Through this paper we want to provide the possibility for generalization of the previously obtained results by answering the same questions over a larger dataset.

\section{RELATED WORK}

A social network ( $\mathrm{SN}$ ) is an online service that allows an individual to create a public profile, connect to other users and access and explore personal and other users' lists of connections [4]. At the moment, Facebook is the largest SN with more than 500 million active users [5] and the second most visited web page [6].

SNs have a mediating effect between individuals and society in the virtual world [15]. They represent a natural technological platform for marketing since they provide access to a large number of users, grouped in communities, based on a structured set of social relationships among admirers of a brand, i.e. a brand community [8]. According to Harris and Rae [9], SNs may play a key role in the future of marketing; they may increase customers' engagement and help to transform the traditional focus on control with a collaborative approach more suitable for the modern business environment. However, traditional advertising techniques are not applicable for the social network platforms, resulting in companies experimenting with many different approaches, thus shaping a 
successful social media strategy based on their own experiences [10].

Previous studies in the field have tried to identify the most influential target group [11] or explain the user relation to the social media [12]. Others have addressed the challenges of social marketing such as aggressive advertisements, lack of ecommerce abilities, invasion of user privacy and legal pitfalls [13]. In addition, companies should avoid overcommercialization of marketing on SNs and favor transparency instead of trying to fully control their image [9]. A company's inappropriate approach to these challenges could lead to a reduction in the number of fans and expose the company to the risk of destroying its own credibility.

Based on exploratory findings and practical examples, scholars have attempted to generate guidelines for successful social marketing. Li [11] recommends that companies need to build an engagement plan before diving into social marketing in order to appropriately approach the frequent users who are most likely to virally spread their enthusiasm for a new product or service. He suggests (1) focusing on having a conversation, (2) developing a close relationship with the brand through "friending" with the social marketing pages, and (3) finding out what interactions, content, and features will keep users coming back. Still, in the domain of Facebook as a platform for social media marketing there are still many open questions on how different companies could fit in with and adhere to the unwritten rules of engagement with the SN communities [2].

Our study analyses the effects caused by the posts shared by the page moderator on a sponsored Facebook brand page in terms of user interactions, such as number of comments and likes, and interaction duration, in order to identify the implications for social media marketing.

\section{THE METHOD}

\section{A. Data Collection and Dataset Characteristics}

Collection of the data for this study was performed using the Facebook Graph API ${ }^{1}$ providing access to the Facebook social graph via a uniform representation of the Facebook social graph. For purpose of this study we have used the Feed connection of the Page object. A Feed connection represents a list of all Post objects containing the following information relevant for our study: (1) the message, (2) the post type, (3) number of likes, (4) number of comments, (5) creation time and (6) time of last interaction.

The gathered data consists of posts from 14 sponsored brand pages. Table I illustrates the high-level characteristics of the selected pages. The data collection was performed on a daily basis over the course of four months, from February, 2011 to June, 2011. This has resulted in 1494 posts. The criteria applied to selecting the set of brand pages consisted of (1) sponsored brand pages, and (2) consumer goods pages. Pages were selected using the Fan Page List ${ }^{2}$ web page which ranks the Facebook pages.
TABle I. Characteristics of Selected Facebook Pages

\begin{tabular}{|l|r|r|r|c|}
\hline \multirow{2}{*}{ Brand } & \multicolumn{2}{|c|}{ Fans } & \multicolumn{2}{c|}{ Posts } \\
\cline { 2 - 5 } & Number $^{a}$ & $\begin{array}{c}\text { Growth } \\
\text { (\%) }\end{array}$ & Number $^{b}$ & $\begin{array}{c}\text { Average } \\
\text { (per day) }\end{array}$ \\
\hline Coca-Cola & 28966208 & $31 \%$ & 50 & 0.42 \\
\hline Disney & 24702363 & $49 \%$ & 71 & 0.59 \\
\hline Dr Pepper & 9409769 & $22 \%$ & 265 & 2.21 \\
\hline Kmart & 425625 & $32 \%$ & 210 & 1.75 \\
\hline M-Budget & 25344 & $2 \%$ & 6 & 0.05 \\
\hline Monster Energy & 10921349 & $32 \%$ & 258 & 2.15 \\
\hline Nutella & 10351315 & $38 \%$ & 15 & 0.13 \\
\hline Oreo & 20405952 & $23 \%$ & 59 & 0.49 \\
\hline Pringles & 14245112 & $60 \%$ & 20 & 0.17 \\
\hline RedBull & 19637223 & $31 \%$ & 96 & 0.80 \\
\hline Starbucks & 22608089 & $16 \%$ & 74 & 0.62 \\
\hline Target & 4597023 & $13 \%$ & 67 & 0.56 \\
\hline Walgreens & 1070345 & $26 \%$ & 111 & 0.93 \\
\hline WalMart & 6212914 & $107 \%$ & 192 & 1.60 \\
\hline & & & $\mathbf{1 4 9 4}$ & $\mathbf{1 2 . 4 5}$ \\
\hline
\end{tabular}

\section{B. Post Categories Assignment}

For this study we have used the same categories as described in [14]. Category assignment was done manually by a single reviewer, in order to remove the bias of different interpretation of the post content. To confirm the validity of the assigned categories and avoid the subjectivity bias, the results were discussed with two additional reviewers.

\section{Used Variables}

Table II explains all of the used independent (IV) and dependent variables (DV) and all of their possible values. The independent variables used for this study are: (1) the post type, (2) the post category, and (3) the weekday of posting. Facebook differentiates between the following post types: (1) status, i.e. text only, (2) photo, containing uploaded photo, (3) link, representing a link to external URL, and (4) video, containing uploaded video. The number of likes $\left(\mathrm{N}_{\mathrm{L}}\right)$ and comments $\left(\mathrm{N}_{\mathrm{C}}\right)$ refer to the total number, regardless of who the commenter/liker was. Since these values are not absolute measures, but are related to the number of page fans $\left(\mathrm{N}_{\mathrm{F}}\right)$ at the moment of posting $\left(\mathrm{T}_{\mathrm{C}}\right)$, we have used the likes ratio (LR) and comments ratio (CR) as a more accurate measure of interaction. Thus, the calculation of the depended variables was performed using the following formulas:

$$
\mathrm{LR}=\mathrm{NL} / \mathrm{NF}_{\mathrm{F}}
$$

$$
\mathrm{CR}=\mathrm{NC} / \mathrm{NF}_{\mathrm{F}} \text {, and }
$$

$$
\mathrm{ID}=\mathrm{T}_{\mathrm{LI}}-\mathrm{T}_{\mathrm{C}}
$$


TABLE II. DEPENDENT AND INDEPENDENT VARIABLES

\begin{tabular}{|c|l|l|c|c|}
\hline Name & \multicolumn{1}{|c|}{ Description } & \multicolumn{1}{|c|}{ Values } & Type & Source \\
\hline PT & Post type & status, photo, video, link & IV & Graph API \\
\hline DOW & Posting day & Monday, ..., Sunday & IV & Graph API \\
\hline PC & Post category & See Chapter III.B & IV & ok.- page \\
\hline LR & Likes ratio & Numerical & DV & Graph API \\
\hline CR & $\begin{array}{l}\text { Comments } \\
\text { ratio }\end{array}$ & Numerical & DV & Graph API \\
\hline ID & $\begin{array}{l}\text { Interaction } \\
\text { duration }\end{array}$ & Numerical & DV & Graph API \\
\hline
\end{tabular}

\section{Data Analysis}

In order to answer our research questions, we have analyzed the effects of each of our independent variables on each of the dependent variables based on statistical testing. We used the Kruskal-Wallis non-parametric test for one-way analysis of variance since the normality tests on both datasets resulted in negative outcome $(\mathrm{CI}=95 \%, \mathrm{p}<0.0001)$. Furthermore, for the post-hoc analysis we have applied the Mann-Whitney test. Finally, the effect size was calculated using the pair-wise comparison based on the Pearson's correlation coefficient.

\section{RESUlts}

\section{A. Post Type}

In the observed dataset all post types were present: status $(399,27 \%)$, photo $(359,24 \%)$, link $(520,35 \%)$ and video $(216$, $14 \%)$. Statistical analysis has shown that there is a significant effect of post type on all three dependent variables, the likes ratio $(\mathrm{H}(3)=389.66, \mathrm{p}<0.0001)$, the comments ratio $(\mathrm{H}(3)=$ $480.64, \mathrm{p}<0.0001)$ and the interaction duration $(\mathrm{H}(3)=$ $117.21, \mathrm{p}<0.0001)$. The results from the post-hoc analysis presented in Table III have identified the sources of the differences as well as the size of the effect.

\section{B. Post Category}

The most common post categories in the observed dataset are Information ( $\mathrm{IN}=674,45 \%)$ and Designed Question $(\mathrm{DQ}=399,27 \%)$. These are followed by Statements (ST=176, $12 \%)$, Advertisements $(\mathrm{AD}=168,11 \%)$ and Competitions $(\mathrm{CO}=71,5 \%)$. The least used post categories are Questionnaires with only two occurrences (QU=2, 0\%) and Announcements with four occurrences $(\mathrm{AN}=4,0 \%)$.

TABLE III. RESUlts OF THE Post TyPe Post-HOC ANALYSIS

\begin{tabular}{|l|l|c|c|c|c|c|c|}
\hline \multicolumn{2}{|c|}{} & \multicolumn{2}{c|}{ LR } & \multicolumn{2}{c|}{ CR } & \multicolumn{2}{c|}{ ID } \\
\cline { 2 - 8 } \multicolumn{2}{|c|}{} & $\boldsymbol{Z}$ & $\boldsymbol{r}$ & $\boldsymbol{Z}$ & $\boldsymbol{r}$ & $\boldsymbol{Z}$ & $\boldsymbol{r}$ \\
\hline Status & Photo & -5.08 & $0.18^{* * *}$ & -6.53 & $0.24^{* * *}$ & -5.23 & $0.19^{* * *}$ \\
\hline Status & Link & -13.77 & $0.45^{* * *}$ & -17.82 & $0.59^{* * *}$ & -5.65 & $0.18^{* * *}$ \\
\hline Status & Video & -8.89 & $0.36^{* * *}$ & -15.43 & $0.62^{* * *}$ & - & - \\
\hline Photo & Link & -17.02 & $0.57^{* * *}$ & -13.11 & $0.44^{* * *}$ & -10.34 & $0.35^{* * *}$ \\
\hline Photo & Video & -11.77 & $0.49^{* * *}$ & -12.61 & $0.53^{* * *}$ & -4.64 & $0.19^{* * *}$ \\
\hline Link & Video & -2.99 & $0.11^{*}$ & -3.42 & $0.13^{*}$ & -5.10 & $0.18^{* * *}$ \\
\hline
\end{tabular}

Similar to the post type, the statistical analysis has revealed that significant effect of post category exists over all three variables, the likes ratio $(\mathrm{H}(6)=218.59, \mathrm{p}<0.0001)$, the comments ratio $(\mathrm{H}(6)=355.90, \mathrm{p}>0.0001)$ and the interaction duration $(\mathrm{H}(6)=25.13, \mathrm{p}<0.0001)$. The post-hoc analysis presented in Table IV reveals the sources of the significant differences between different post categories.

\section{Posting Day}

Our dataset shows relatively uniform distribution of moderator posts over different days of the week. Fridays (260, $17 \%)$ and Wednesdays $(256,17 \%)$ are the top two days for posting. These are followed by Thursdays (232, 15\%), Mondays $(228,15 \%)$ and Tuesdays $(211,14 \%)$. Saturdays (146, 10\%) and Sundays (161, 10\%) show lowest level of activity from the moderator side.

In this case the statistical analysis showed no significant effect of the over the likes ratio $(\mathrm{H}(6)=5.39, \mathrm{p}=0.495)$ and the comments ratio $(\mathrm{H}(6)=9.54, \mathrm{p}=0.146)$. An effect was found to exist only over the interaction duration $(\mathrm{H}(6)=17.06$, $\mathrm{p}=0.009)$. The post-hoc analysis has shown that the difference exists only between posts shared on Tuesday and Friday $(\mathrm{Z}=$ $2.14, \mathrm{p}=0.033, \mathrm{r}=0.09)$, and Sunday and, Monday $(Z=3.04$, $\mathrm{p}=0.002, \mathrm{r}=0.15)$, Wednesday $(\mathrm{Z}=-2.73, \mathrm{p}=0.006, \mathrm{r}=$ $0.13)$, Thursday $(\mathrm{Z}=-2.17, \mathrm{p}=0.03, \mathrm{r}=0.10)$, Friday $(\mathrm{Z}=-$ 3.82, $\mathrm{p}<0.0001, \mathrm{r}=0.18)$ and Saturday $(\mathrm{Z}=-2.65, \mathrm{p}=0.008$, $\mathrm{r}=0.15)$. The effect size for all pairs is very small.

\section{DISCUSSION AND CONCLUSIONS}

In this paper we present the results of the evaluation of the effect of the post characteristics: type, category and posting day on the user interaction level in terms of number of comments, likes and interaction duration. The analysis was performed over data collected from 14 different Facebook brand pages over the period of four months. The goal of this study was to confirm the previous findings from a case study over a single Facebook brand page [14] in order to provide the possibility for generalization of the previously obtained results.

TABLE IV. RESUlts OF THE POST CATEgORY POST-HOC ANALYSIS ${ }^{\mathrm{A}}$

\begin{tabular}{|l|l|c|c|c|c|c|c|}
\hline \multicolumn{2}{|c|}{} & \multicolumn{2}{c|}{ LR } & \multicolumn{2}{c|}{ CR } & \multicolumn{2}{c|}{ ID } \\
\cline { 2 - 8 } \multicolumn{2}{|c|}{} & $\boldsymbol{Z}$ & $\boldsymbol{R}$ & $\boldsymbol{Z}$ & $\boldsymbol{r}$ & $\boldsymbol{Z}$ & $\boldsymbol{R}$ \\
\hline ST & DQ & -8.76 & $0.37^{* * *}$ & -6.17 & $0.26^{* *}$ & - & - \\
\hline ST & IN & -11.96 & $0.41^{* * *}$ & -10.91 & $0.37^{* * *}$ & - & - \\
\hline ST & CO & -9.72 & $0.62^{* * *}$ & -3.34 & $0.21^{* *}$ & - & - \\
\hline DQ & IN & -4.59 & $0.14^{* * *}$ & -16.62 & $0.50^{* *}$ & -3.66 & $0.11^{* * *}$ \\
\hline DQ & CO & -5.65 & $0.26^{* * *}$ & -5.64 & $0.26^{* * *}$ & -2.56 & $0.12^{*}$ \\
\hline DQ & AD & -5.42 & $0.23^{* * *}$ & -6.29 & $0.26^{* * *}$ & - & - \\
\hline AN & IN & -1.98 & $0.07^{*}$ & - & - & - & - \\
\hline AN & CO & -2.76 & $0.32^{*}$ & - & - & - & - \\
\hline IN & CO & -3.58 & $0.13^{*}$ & - & - & & \\
\hline IN & AD & -8.17 & $0.28^{* * *}$ & -9.40 & $0.32^{* * *}$ & -3.69 & $0.13^{* * *}$ \\
\hline CO & AD & -7.37 & $0.48^{* * *}$ & -2.77 & $0.18^{*}$ & -2.82 & $0.18^{*}$ \\
\hline
\end{tabular}


The results presented in the previous section have shown that different post characteristics cause different effect on the level of user interaction on the Facebook page. Post type had effect on all three interaction measures, the likes ratio $(p<$ $0.0001)$, the comments ratio $(\mathrm{p}<0.0001)$ and the interaction duration $(p<0.0001)$. Status posts caused the greatest number of comments, while videos caused the most likes. Photos and links had the least interaction in both cases. Interaction duration on photos was longest, followed by status, video and link posts. These results differ compared to the previous findings where photos were the source of greatest interaction for all three measures. This difference is partly due to the fact that in our previous study video posts were not present in the dataset, resulting in incomplete results.

In case of post category, significant effect was found to exist on all three variables, the likes ratio $(\mathrm{H}(6)=218.59, \mathrm{p}<$ $0.0001)$, the comments ratio $(\mathrm{H}(6)=355.90, \mathrm{p}>0.0001)$ and the interaction duration $(\mathrm{H}(6)=25.13, \mathrm{p}<0.0001)$. Posts containing Information have caused the significantly larger number of likes compared to other post categories. The least number of likes occurred for posts related to Competitions. Posts with a goal of engagement, i.e. Designed Questions have resulted in significantly larger comments ratio, while Statements were the last in the categories list. These results differ from those obtained from the previous study where Advertisements and Announcements have caused the greatest level of interaction. This difference relates to the fact that in our case study we have analyzed an emerging brand, with a large number of new product launches during the observation period, while the Facebook pages used for this study are already established on the market for a long period of time. In terms of interaction duration, Questioners and Advertisements have caused the longest interaction, while Announcements had the shortest interaction duration. This again differs from the previous results.

Posting day was shown to have again a very small effect. In addition, the effect was visible only for interaction duration as opposed to the observed effect over the comments ratio obtained from the previous study. Since this introduces a significant difference in the results a final conclusion regarding the influence of the posting day cannot be drawn.

The results of this study comply with the previous results on a global level. However, the details presented in the posthoc analysis differ between both datasets. The manual investigation of the posts during the category assignment has revealed that posts belonging to same type or category significantly differ in terms of the topic referred to within the posts. For example, Information posts from the case study were mostly related to sales or products, while in the larger dataset many posts of this category were reflecting recent events, such as sport events, movies, the British royal wedding, etc.

Based on these results and observations we could show clear evidence of different moderator post characteristics causing different level of fan activity. However, a final conclusion can't be drawn in terms of which post type or category will cause the greatest level of interaction. This should encourage moderators of Facebook pages to prepare clear posting strategies with set goals for the measurements presented in this paper in order to trigger the activity of users which in turn constitutes marketing success and increased purchasing behavior. Furthermore, since different communities may respond differently to same post characteristics, we propose iterative measuring and monitoring of the activities with a goal of shaping the posting strategy towards the specific interests of the targeted community, i.e. the Facebook brand page fans. This activity should be implemented as a part of the social media marketing strategy.

\section{FUTURE WORK}

The manual inspection of the posts during the category assignment and the statistical analysis of the post differences in page characteristics showed different posting strategies by the moderators. These refer to the average number of posts per day, different frequencies of post types and categories and different topics referred to within the same post category. We assume that these factors have influence over the user interaction and will be taken in consideration in the future steps of our analysis. Finally, we would like to compare our results to those from different categories of Facebook pages.

\section{REFERENCES}

[1] K. S. Brandt, "You should be on YouTube," in ABA Bank Marketing, vol. 40(6), 2008, pp. 28-33.

[2] D. Richter, K. Riemer, and J. vom Brocke, "Internet social networking: Research state of the art and implications for Enterprise 2.0," in Business \& Information Systems Engineering, March 2011.

[3] A. Palmer, and N. Koenig-Lewis, "An experiential, social networkbased approach to direct marketing," in Direct Marketing: Int. J., vol. 3 (3), 2009, pp. 162-176.

[4] D. M. Boyd, and N. B. Ellison, "Social network sites: Definition, history, and scholarship," J. Comput.-Mediated Commun., vol. 13(1), 2008, pp. 210-230.

[5] Facebook Statistics [Online]. http://www.facebook.com/press/info.php?statistics

[6] Alexa.com [Online]. Available: http://www.alexa.com

[7] C. Lampe, N. Ellison, and C. Steinfield, "A Face(book) in the crowd: Social searching vs. social browsing," in Proc. 20th Anniversary Conf. Comput. Supported Cooperative Work, 2006, pp. 167-170.

[8] A. M. Muniz, Jr., and T. C. O’Guinn, "Brand Community," J. Consumer Research, vol. 27(4), 2001, pp. 412-432.

[9] L. Harris, and A. Rae, "Social networks: the future of marketing for small business," J. Bus. Strategy, vol. 30(5), 2009, pp. 24-31.

[10] M. Coon, "Social media marketing: Successful case studies of businesses using Facebook and YouTube with an in-depth look into the business use of Twitter. M.A. thesis. Dept. Commun. Stanford Univ., Stanford, CA, 2010.

[11] C. Li. (2007). How consumers use social networks. Forrester Research Paper [Online]. Available: http://www.eranium.at/blog/upload/consumers_socialmedia.pdf

[12] A. L. Agozzino, "Millennial students relationship with 2008 top 10 social media brands via social media tools" Ph.D. dissertation, Dept. Mass Commun. Bowling Green State Univ., Bowling Green, OH, 2010.

[13] V. Bolotaeva, and T. Cata, "Marketing opportunities with social networks," J. Internet Social Networking and Virtual Communities, 2010.

[14] I. Pletikosa Cvijikj, and F. Michaheles. "A Case Study of the Effects of Moderator Posts within a Facebook Brand Page," in Proc. 3rd Int. Conf. Social Informatics, 2011, in press.

[15] S. Wasserman, and K. Faust, Social network analysis: Methods and applications. Cambridge University Press, Cambridge, 1994. 